\title{
Occupational disability on psychiatric grounds in South African school-teachers
}

\author{
R Emsley, L Emsley, S Seedat \\ Department of Psychiatry, Faculty of Health Sciences, University of Stellenbosch, Cape Town, South Africa
}

\begin{abstract}
Objective: School-teachers are exposed to high levels of stress and have high rates of premature retirement on psychiatric grounds. This study investigated factors associated with occupational disability due to psychiatric disorders in teachers in South Africa. Method: This retrospective study investigated 81 school-teachers in the Cape Town area who had been declared permanently medically disabled as a consequence of psychiatric disorders. Results: Patients were relatively young (44 \pm 6.1 yrs), had experienced symptoms for $5.2 \pm 3.8 \mathrm{yrs}$, and had been treated for $4 \pm 3.5 \mathrm{yrs}$. Almost half had a family history of psychiatric disorder, and the majority ( $\mathrm{N}=66.81 \%$ ) cited work-related stress as a significant contributing factor. Major depressive disorder was the commonest diagnosis (83\%), and 56\% had co-morbid Axis-I diagnoses. Thirty percent had prominent underlying obsessive-compulsive personality traits, and $46 \%$ displayed classroom phobia. Conclusion: Work-related stress is a major factor in South African teachers with occupational disability on psychiatric grounds.
\end{abstract}

Key words: School-teachers; Disability; Occupation

Received: 15-08-2008

Accepted: 01-09-2008

\section{Introduction}

It is generally recognised that teachers experience high levels of stress, and that this in turn results in high levels of mental health problems. ${ }^{1}$ For example, a study in working German school-teachers found that 33\% suffered from "burnout syndrome", and a further 18\% from "severe strain". These teachers regarded high numbers of learners in classrooms and destructive and aggressive behaviour of learners as the primary stress factors. ${ }^{2}$ Johnstone ${ }^{3}$ reported that major causes of stress amongst school-teachers are: learners' failure to work or to behave, poor working conditions, poor relationships with colleagues, work overload or excessive routine work, and poor school ethos. Teachers themselves generally perceive their job to be stressful ${ }^{4}$, and regard work-load as the most anxiety-inducing and fatiguing problem ${ }^{5}$, although relationships with staff have also been frequently cited. ${ }^{6}$ As would be expected, changes in the educational dispensation have also been associated with teacher stress. ${ }^{\text {? }}$

Excessive stress and resultant psychiatric disorders are likely to lead to increased absenteeism and early retirement

\section{Correspondence:}

Prof R Emsley

University of Stellenbosch, Department of Psychiatry,

PO Box 19063, Tygerberg, 7505, South Africa

email: tae@sun.ac.za from the teaching profession. ${ }^{7}$ The extent of the problem may be considerable. In fact, a study in England indicated that psychiatric disorders are the largest cause of early retirement amongst teachers. This study surveyed a randomly selected sample of 570 retired teachers, asking respondents to classify their illness at retirement. Psychiatric disorders were most frequently cited (52\% of male and $42 \%$ of female teachers who retired early did so because of mental health difficulties). ${ }^{8}$ Similarly, psychosomatic disorders and so-called "burnout syndrome" were the main cause of increasing rates of premature retirement of school-teachers in Germany. ${ }^{2}$

Teachers in South Africa may be particularly at risk for stress-related psychiatric disorders. Socio-political changes in South Africa over the past decade and more have placed extra-ordinary levels of stress on people in many occupational sectors, including the teaching profession. Educational reform has been central to the country's reconstruction and development project since the first democratic elections in 1994. The old, racially based educational system had to be replaced by a system of education emphasising human dignity, equality and social justice. At the same time, a culture of lifelong learning had to be established to enable South Africans to respond appropriately to the economic and social challenges of the 21 st century. ${ }^{9}$ This transformation had to take place with limited funding and resources. It could be 
anticipated therefore that these changes would place an additional burden on school-teachers. In fact, alarmingly high levels of dissatisfaction have been reported amongst South African teachers. According to a recent comprehensive survey conducted on 21358 teachers in South Africa, more than half (55\%) have seriously considered leaving the profession. The reasons given included inadequate remuneration, increased work-load, lack of career development or professional recognition, dissatisfaction with work policies, job insecurity and lack of choice as to where to work. The respondents most likely to leave were non-Africans, men, those aged 25 to 49 years, the best qualified, and those teaching technology, economics and management, and natural sciences. ${ }^{10}$

While several studies on the nature and consequences of stress in teachers have appeared in the educational literature, few have focused upon psychiatric consequences of the stress, and very little has been published in the medical/psychiatric literature. We conducted a study in which we investigated 81 members of the teaching profession who had been declared permanently medically disabled as a consequence of psychiatric disorders.

\section{Method}

This was a retrospective chart review of subjects who had been assessed by a psychiatrist (RE) as part of their evaluation for medical disability. The study was submitted to the Institutional Review Board of the University of Stellenbosch and exemption from ethical approval was granted. Participants were all secondary-school teachers residing in or near Cape Town who had been declared medically disabled on psychiatric grounds between 1997 and 2006. Only subjects with an Axis I DSM-IV diagnosis ${ }^{11}$ were included. Assessments included a semistructured psychiatric interview, review of the available medical and psychiatric reports, and collateral information from family members where this was available. Data were analysed using Statistica Version 7 (Statsoft) software. Student's t-tests (for continuous variables) and Chi-square tests (or Fisher exact tests) (for categorical variables) were used to compute selected group differences. Pearson product moment correlation coefficients were sought between continuous variables. A significance level of .05 was used throughout. In view of the exploratory nature of this study, we did not apply corrections for multiple testing.

\section{Results}

The sample comprised 55 (68\%) women and 26 (32\%) men. Details of their age, duration of service, duration of symptoms, duration of treatment and global assessment of functioning are

Table I. Details of the age, duration of service, duration of symptoms, duration of psychiatric treatment and Global Assessment of Functioning scores for the 81 occupationally disabled teachers

\begin{tabular}{|l|l|l|l|l|}
\hline & Mean & SD & Min & Max \\
\hline Age (years) & 44 & 6.1 & 33 & 58 \\
Duration of service (years) & 20 & 6.1 & 8 & 34 \\
Duration of symptoms (years) & 5.2 & 3.8 & 1 & 20 \\
Duration of treatment (years) & 4 & 3.5 & 1 & 20 \\
Global Assessment of Functioning scores & 65 & 8.3 & 50 & 90 \\
(N=31) & & & & \\
\hline
\end{tabular}

provided in Table I, and psychiatric and marital history are provided in Table II. Table III lists the frequency and nature of significant contributory stress factors cited by the subjects. DSM-IV diagnoses given in Table IV, and details of treatment in Table V.

Table II. Psychiatric history and marital status of the 81 occupationally disabled teachers

\begin{tabular}{|l|l|l|}
\hline & N & $\%$ \\
\hline Family history of psychiatric disorders & 37 & $46 \%$ \\
Previous psychiatric disorders & 10 & $12 \%$ \\
Married & 64 & $79 \%$ \\
Single & 6 & $7 \%$ \\
Divorced & 7 & $9 \%$ \\
Widowed & 4 & $5 \%$ \\
\hline
\end{tabular}

Table III. The frequency and nature of contributory stress factors cited by the 81 occupationally disabled teachers

\begin{tabular}{|l|l|l|}
\hline & N & $\%$ \\
\hline Work-related stress & 66 & $81 \%$ \\
Classroom discipline problems & 38 & $47 \%$ \\
Work-overload & 15 & $19 \%$ \\
Conflict with colleagues & 11 & $14 \%$ \\
Restructuring of staff establishments & 10 & $12 \%$ \\
Large classes & 6 & $7 \%$ \\
Other, non-school related stressors & 23 & $29 \%$ \\
\hline
\end{tabular}

Table IV. Psychiatric diagnoses of the 81 occupationally disabled teachers

\begin{tabular}{|l|l|l|}
\hline & $N$ & $\%$ \\
\hline Major depressive disorder & 67 & $83 \%$ \\
Panic disorder & 29 & $36 \%$ \\
Agoraphobia & 25 & $31 \%$ \\
Generalised anxiety disorder & 8 & $10 \%$ \\
Substance dependence & 2 & $2 \%$ \\
Posttraumatic stress disorder & 2 & $2 \%$ \\
Bipolar mood disorder & 5 & $6 \%$ \\
Dementia & 1 & $1 \%$ \\
Schizophrenia & 1 & $1 \%$ \\
Obsessive compulsive disorder & 1 & $1 \%$ \\
Social phobia & 1 & $1 \%$ \\
Conversion disorder & 1 & $1 \%$ \\
Intermittent explosive disorder & 1 & $1 \%$ \\
More than one Axis-l diagnosis & 45 & $56 \%$ \\
Obsessive-compulsive personality traits & 24 & $30 \%$ \\
"Classroom phobia" & 37 & $46 \%$ \\
\hline
\end{tabular}

Table V. Details of treatment received by the 81 occupationally disabled teachers

\begin{tabular}{|l|l|l|}
\hline & $N$ & $\%$ \\
\hline Treated by a psychiatrist & 80 & $99 \%$ \\
Received antidepressant medication & 78 & $96 \%$ \\
Hospitalised & 54 & $67 \%$ \\
Individual psychotherapy by psychologist & 71 & $88 \%$ \\
\hline
\end{tabular}


When we investigated associations between demographic and clinical factors we found that age and years of teaching experience were significant in several respects. Younger disabled teachers were more likely to cite unfavourable workcircumstances $(\mathrm{t}=-2.2, \mathrm{df}=79, \mathrm{p}=.03)$ and specifically work overload ( $t=2.0, \mathrm{df}=79, \mathrm{p}=.04$ ) as contributory factors. Subjects with fewer years of experience were more likely to cite unfavourable work-circumstances $(t=-2.3, \mathrm{df}=79, \mathrm{p}=$ .03), specifically work overload ( $t=2.3, d f=79, p=.02)$ and issues related to re-structuring of the educational dispensation $(\mathrm{t}=-2.5, \mathrm{df}=79, \mathrm{p}=.01)$ as contributory factors, and were more likely to have agoraphobia $(t=2.4, d f=79, p=.02)$. On the other hand, stressors not related to work were more common in subjects with a longer duration of symptoms ( $t=$ 3.9, $\mathrm{df}=78, \mathrm{p}=.0002$ ) and in those who had been treated over a longer time $(t=-3.1, d f=78, p=.003)$. Also, patients with prominent obsessive-compulsive traits were more likely to be older $(t=2.1, d f=79, p=04)$. As would be expected, age was significantly correlated with years of service $(r=.77$, $\mathrm{p}=0001)$, and duration of treatment was significantly correlated with duration of symptoms ( $r=.9, \mathrm{p}=0001)$. Women were more likely to be younger than their male counterparts $(t=-2.6, d f=79, p=.01)$. There were additional significant associations between a positive family history of psychiatric disorder and the presence of work related stress (chi-square $=5.7, \mathrm{df}=1, \mathrm{p}=.02$ ), large classes (chi-square = 3.7, $\mathrm{df}=1, \mathrm{p}=.05$ ), and non work-related stressors (chisquare $=4.9, \mathrm{df}=1, \mathrm{p}=.03)$

\section{Discussion}

Psychiatric disorders as a cause of occupational disability are under-recognised and under-treated. ${ }^{12}$ In Canada, disability claims related to psychiatric disorders have doubled in recent years, accounting for $30 \%$ of all disability claims at a cost of billions of dollars annually. ${ }^{13}$ In Finnish men, $17 \%$ of all disability pensions were due to a psychiatric disorder, of which 53\% were for depression. ${ }^{14}$ Similarly, in South Africa there has been an alarming increase in applications for medical disability on psychiatric grounds, likely related in many cases to the socio-political changes that have been taking place. ${ }^{15}$ People in jobs with a high social and ethical responsibility - such as teaching - may be particularly at risk for developing stress-related disorders. ${ }^{2}$ While this study was not designed to assess the prevalence of psychiatric disorders amongst school-teachers, it was our general impression that, together with members of the security services ${ }^{16}$, schoolteachers in South Africa were over-represented in applications for medical disability on psychiatric grounds. It was this observation that spurred us to conduct this study.

The vast majority (81\%) of our subjects cited work-related stress as a significant factor in the development of their psychiatric disorders. A lack of discipline amongst learners and work-overload were the most common stressors. This is consistent with studies in Western countries. ${ }^{2-4}$ Interestingly, few subjects (12\%) singled out the restructuring of staff establishments (including poor career opportunities due to affirmative action policies) as a significant factor - in contrast to a previous study of ours in members of the South African security forces. ${ }^{16}$ The recognition and acknowledgement by authorities of stressful work circumstances is important, as disability management programs implementing stress- management interventions have been found to improve physical and mental health and facilitate the return of individuals into the work environment, with reduced costs to employers. ${ }^{17}$

The results of this study suggest that certain factors may predispose school-teachers to the development of stressrelated psychiatric disorders. First, many of our subjects were young. The mean age of our sample of 44 yrs is considerably lower than that reported in a Finnish study for example, where the mean age for retirement for men with depression was 57.6 yrs. ${ }^{14}$ Younger and less experienced teachers were more likely to be negatively affected by stressful work circumstances, particularly work overload and changes related to the transformation of the services. (On the other hand, in older teachers stressors not related to work were more likely to play a role.) This is an unexpected finding, as it would be expected that teachers who had been in the previous dispensation longer would have greater difficulty adjusting to the changes that have taken place. Indeed, a previous study found older age to be a significant contributing factor in occupationally disabled patients with major depressive disorder. ${ }^{18}$ One possible explanation for our finding is that younger teachers had greater expectations, and were subsequently more dissatisfied with aspects such as those highlighted by the recent South African survey, namely inadequate remuneration, increased work-load, lack of career development or professional recognition, dissatisfaction with work policies, job insecurity and lack of choice as to where to work. The relatively young age of our subjects is also consistent with the finding from the survey that South African teachers aged 25 to 49 years are most likely to leave the profession. ${ }^{10}$ Second, the high proportion of our subjects with a positive family history of psychiatric disorder (46\%), suggests that this may be an important risk factor. And third, certain personality traits may predispose some teachers to the development of psychiatric disorder under stressful work-circumstances. A previous study found that personality factors contributed more to stress levels in teachers than did the variables of either age or gender. ${ }^{19}$ We found that a high proportion (30\%) of the teachers in our sample had prominent obsessive-compulsive personality traits. Under normal circumstances people with obsessivecompulsive personality traits would be expected to do well as teachers. In fact, compared with other personality dimensions, patients with obsessive-compulsive personality traits showed the least degree of functional impairment, and actually showed a significant negative correlation with impairment in employment. ${ }^{20}$ However, while people with obsessivecompulsive personality traits are likely to show excessive devotion to work and productivity they are also likely to experience difficulties and distress when confronted with new situations that demand change. ${ }^{11}$ It may be therefore, that teachers with this personality type found it particularly difficult to adapt to the rapid changes that took place in the educational system in South Africa.

Major depressive disorder was the most commonly diagnosed DSM-IV axis-I disorder in our study (83\%). This was not surprising, given that major depression is the dominant psychiatric disorder causing functional and work disability ${ }^{18}$, and is reported to be the fastest increasing reason for early retirement. ${ }^{14}$ In a study in the United States, 1.8 to $3.6 \%$ of all workers in the labour force suffered from major 
depression, which had a significant impact on vocational functioning. ${ }^{21}$ Studies in patients with major depressive disorder have found that the most important factors associated functional and work disability were the severity of depression, previous episodes of depression, incomplete response to treatment, and longer duration of symptoms. Other significant factors were older age, neurotic personality traits, perceived social support and the presence of co-morbid psychiatric disorders. ${ }^{18 ; 22}$ Concerning the latter, there was also a high rate of co-morbid axis-I diagnoses in our subjects. The most commonly occurring combination was that of major depressive disorder, panic disorder and agoraphobia ( $n=21$, 26\%). Another study suggests that co-morbidity predicts greater occupational impairment - in a sample of adult primary care outpatients, compared to patients with a single psychiatric disorder, those with co-occurring disorders had greater impairment of social and occupational functioning. ${ }^{23}$

Another interesting finding was that almost half of the patients (46\%) displayed what can best be described as classroom phobia - intense fear for, and avoidance of the classroom situation. Anecdotally, this appeared to be a major contributor to absenteeism, and complicated attempts to return to work.

\section{Conclusion}

The retrospective nature of this study, the absence of a control group and the lack of standard assessment instruments are limiting factors. Also, these findings cannot be generalised to school-teachers worldwide. However, our study highlights the need for more research into stress-related psychiatric morbidity in school-teachers. It suggests that work-related stress is a major contributory factor in the majority of cases of occupational disability on psychiatric grounds, and that younger age, a family history of psychiatric disorder and obsessive-compulsive personality traits may be important risk factors. Our findings should serve as a further warning to education authorities, and steps should be taken to protect the mental health of seemingly "at risk" teachers working in South African schools. Such steps should include addressing specific stressors such as classroom discipline and work overload, increasing awareness amongst teachers and authorities, and early identification and appropriate management of those teachers who develop psychiatric disorders.

\section{References}

1. Pithers ST, Soden R. Scottish and Australian teacher stress and strain: a comparative study. British Journal of Educational Psychology 1998;68: 269-279.

2. Bauer J, Stamm A, Virnich K, et al. Correlation between burnout syndrome and psychological and psychosomatic symptoms among teachers. Int Arch Occup Environ Health 2006; 79: 199-204.

3. Johnstone M. Stress in Teaching: An overview of research. In: The
Scottish Council for Research in Education, ed. Edinburgh: 1989.

4. Johnstone M. Stress in Teaching: A return to the questions. In: The Scottish Council for Research in Education, ed. Edinburgh: 1993.

5. Dewe P, Guest D, Williams R. Methods of Coping with Work related Stress. In: Mackay, Cox, eds. Response to Stress: Occupational aspects. IPC Science and Technology Press; 1979.

6. Cooper CL, Kelly M. Occupational Stress in Head Teachers: A national UK study. British Journal of Educational Psychology 1993; 63:130-143.

7. Wilson V. Feeling the strain: An overview of the literature on teacher's stress. In: The Scottish Council for Research in Education, 2002: report no. 109.

8. Bowers T, McIver M. Ill Health Retirement and Absenteeism Amongst Teachers. 235 ed. London: Department of Education and Employment; 2000:report no.235.

9. Education Change and Transformation in South Africa: A Review 1994-2001. Pretoria: Department of Education; 2001.

10. Hall E, Altman M, Nkomo N, et al. Potential Attrition in Education: The impact of job satisfaction, morale, workload and HIVIAIDS. Cape Town: HSRC Press; 2005.

11. American Psychiatric Association. Diagnostic and Statistical Manual of Mental Disorders. IV ed. American Psychiatric Association; 1994.

12. Bender A, Kennedy S. Mental health and mental illness in the workplace: diagnostic and treatment issues. Healthc Pap 2004; 5: 5467.

13. Dewa CS, Lesage A, Goering P, et al. Nature and prevalence of mental illness in the workplace. Healthc Pap 2004; 5: 12-25.

14. Karpansalo M, Kauhanen J, Lakka TA, et al. Depression and early retirement: prospective population based study in middle aged men. J Epidemiol Community Health 2005; 59: 70-74.

15. Emsley R, Coetzer P. Disability claims on psychiatric grounds. S Afr Med J 1996; 86: 646.

16. Emsley RA, Seedat S, Stein DJ. Posttraumatic stress disorder and occupational disability in South African Security Force members. J Nerv Ment Dis 2003; 191: 237-241.

17. Jones DL, Tanigawa T, Weiss SM. Stress management and workplace disability in the US, Europe and Japan. J Occup Health 2003; 45: 1-7.

18. Rytsala HJ, Melartin TK, Leskela US, et al. Functional and work disability in major depressive disorder. J Nerv Ment Dis 2005; 193 : 189-195.

19. Fontana $D$, Abouserie R. Stress levels, gender and personality factors in teachers. Br J Educ Psychol 1993; 63 (Pt 2): 261-270.

20. Skodol AE, Oldham JM, Bender DS, et al. Dimensional representations of DSM-IV personality disorders: relationships to functional impairment. Am J Psychiatry 2005; 162:1919-1925.

21. Goldberg RJ, Steury S. Depression in the workplace: costs and barriers to treatment. Psychiatr Serv 2001; 52: 1639-1643.

22. Rytsala HJ, Melartin TK, Leskela US, et al. Determinants of functional disability and social adjustment in major depressive disorder: a prospective study. J Nerv Ment Dis 2006; 194: 570-576.

23. Olfson $M$, Fireman B, Weissman MM, et al. Mental disorders and disability among patients in a primary care group practice. Am J Psychiatry 1997; 154: 1734-1740. 